OPEN ACCESS

Edited by:

Kristiina Kumpulainen,

University of Helsinki, Finland

Reviewed by:

Skulina Hlif Kjartansdottir,

University of Iceland, Iceland Jon Mason,

Charles Darwin University, Australia

${ }^{*}$ Correspondence: Bronwyn Bevan bronwynb@uw.edu

Specialty section:

This article was submitted to

STEM Education

a section of the journal

Frontiers in Education

Received: 24 February 2020

Accepted: 17 June 2020

Published: 02 September 2020

Citation:

Bevan B, Ryoo JJ, Vanderwerff A, Wilkinson K and Petrich M (2020) "I See Students Differently": Following the Lead of Maker Educators in Defining What Counts as Learning. Front. Educ. 5:121

doi: 10.3389/feduc.2020.00121

\section{"I See Students Differently": Following the Lead of Maker Educators in Defining What Counts as Learning}

\author{
Bronwyn Bevan ${ }^{1 *}$, Jean J. Ryoo ${ }^{2}$, Aaron Vanderwerff ${ }^{3}$, Karen Wilkinson ${ }^{4}$ and \\ Mike Petrich ${ }^{4}$
}

${ }^{1}$ College of Education, University of Washington, Seattle, WA, United States, ${ }^{2}$ Graduate School of Education and Information Studies, University of California, Los Angeles, Los Angeles, CA, United States, ${ }^{3}$ Maker Ed, San Mateo, CA, United States,

${ }^{4}$ Exploratorium, San Francisco, CA, United States

With the expansion of maker programs in school and out-of-school settings, investigating the connections between making and learning is important for many reasons, not least to build the evidence base needed by educators committed to its practice. In this paper, we argue that, as a relatively new area of inquiry, studies of making can benefit from close dialogue between researchers and the practitioners who have pioneered and continue to develop the practice. We share how a research-practice partnership sought to amplify the voices of informal educators leading afterschool maker programs to address the research question: How can afterschool maker programs support student learning that is valued and relevant to the school day? We show how the research-practice partnership helped to refine a pedagogical framework describing learning dimensions of making and tinkering in ways that reflect the values and expert knowledge of informal educators committed to liberatory forms of education for young people, particularly those from socio-economically and racially marginalized communities.

Keywords: STEM, tinkering, concept map, afterschool, research-practice partnership (RPP), expansive learning, rightful presence, maker education

\section{INTRODUCTION}

The pedagogy of making has a long history but only in the last decade has it garnered the widespread attention of education researchers: launching conferences, special interest groups, and special issues of journals like this one. Making is an age-old human practice and school-based making pedagogies, from Pestalozzi to Dewey to Montessori to Papert, have a rich history. But since 2008, as digital screens have proliferated in the lives of children and families, perhaps prompting a sense of nostalgia for a simpler mechanical age and childhood, the Maker Movement, with significant political and marketing support, has come to redefine what hands-on learning can look like in many educational settings.

Making, as an educational activity, provides raw materials to young people and invites them to ideate, design, and build out their ideas (Blikstein, 2013; Martin, 2015). Making has been characterized as having "high ceilings, low floors, and wide walls" (Resnick and Silverman, 2005), and as such many have argued that it is well-positioned to broaden participation in learning, particularly science and engineering learning (e.g., Buchholtz et al., 2014). Others have argued that without careful attention to the pedagogy of making, it can be experienced as reinforcing dominant 
cultural norms about who does science and what science looks like (Vossoughi et al., 2016; Bevan, 2017; Calabrese Barton and Tan, 2018).

With the expansion of maker programs in school and outof-school settings, investigating the connections between making and learning is important for many reasons, not least to build the evidence base needed by educators committed to its practice (Petrich et al., 2013; Iversen et al., 2016; Peppler et al., 2016). In this paper, we argue that, as a relatively new area of inquiry, studies of making can benefit from close dialogue between researchers and the practitioners who have pioneered and continue to develop the practice. We share how a researchpractice partnership sought to amplify the voices of informal educators leading afterschool maker programs to address the research question: How can afterschool maker programs support student learning that is valued and relevant to the school day? We show how the research-practice partnership helped to refine a learning dimensions framework in ways that reflect the values and expert knowledge of informal educators committed to liberatory forms of education for young people, particularly those from socio-economically and racially marginalized communities.

\section{METHODOLOGICAL AND THEORETICAL APPROACHES}

\section{Research-Practice Partnerships}

Research-practice partnerships (RPPs) have been posited as a mechanism for producing more equitable and ethical research practices (Bevan and Penuel, 2018; Kirshner et al., 2018). RPPs are defined as studies that (1) address persistent problems of practice that are (2) of mutual importance and benefit to both researchers and practitioners. They (3) take place over time with an open-ended commitment to working together, (4) making systematic use of structures intentionally designed to foster relationships. And (5) they involve original data collection and analysis (Coburn and Penuel, 2016). They have been described as a powerful tool for democratizing the production and use of evidence in education (Tseng et al., 2018).

The maker-focused RPP described here was a partnership between a science museum and a K-12 public charter school in the San Francisco Bay Area. Eighty-five percent of students at the school came from low-income families, $80 \%$ were Emergent Bilinguals, $90 \%$ would be the first in their families to go to college. Some $79 \%$ of students identified as Latinx, 12\% African American, 3\% Asian, and 6\% White or Multiracial. The project involved a weekly afterschool tinkering class, co-taught by an afterschool educator and a museum educator, for roughly a dozen middle school aged youth. We define "tinkering" as processes of making that are intentionally designed to require and encourage creative and improvisational problem-solving, vs. step-by-step construction where, if done correctly, will always reach the same, correct final form (Resnick and Rosenbaum, 2013; Bevan et al., 2015; Berland, 2016). Many maker programs interweave these two approaches to support both skill building and creative invention. The youth who participated in this study chose the tinkering afterschool class over other maker-oriented and non-maker afterschool options, such as musical composition, cooking, film critique, art, or "weird science."

The goals of the RPP were of mutual interest and importance to educators from both the museum and the school. The Oakland, CA-based school, which had been founded a decade earlier on progressive education principles, had been integrating making into school-day classrooms and afterschool programs for the previous five years. But, during a decade dominated by high-stakes testing, its maker programs had become increasingly relegated to afterschool time and electives. The third author, whose administrative responsibilities involved supporting learner-driven practices across school-day and afterschool time, was interested in documenting the power of the afterschool maker programs in order to inspire more school-day focus on learner-driven teaching practices. The museum team of researchers and practitioners had over the years conducted several studies of the power of tinkering in the museum and other informal settings (Bevan et al., 2015, 2017; Bevan, 2019). They had produced a first generation learning dimensions framework developed in the museum setting (Bevan et al., 2015; Gutwill et al., 2015), and were eager to explore and articulate how such learning was also of value to school-day educators.

The students enrolled in the afterschool tinkering class changed slightly over the three semesters, but were mostly female, and mostly in 4th and 5th grade. A total of 20 students participated in all three semesters of the tinkering class, with more than half participating in all three semesters. Each semester focused on a different science theme: Circuitry, Cause-and-Effect, and Optics. Over 8 weeks each semester, students engaged in 4-6 multi-session tinkering activities that built on lessons learned in previous sessions. For example, the circuits semester started with one-dimensional paper circuits and expanded to explore parallel and series circuits, sewn and wearable circuits, and ultimately three-dimensional installations integrating circuitry, storytelling, and design.

The tinkering co-teachers met each week with the researcher leading data collection, the second author, to reflect on the prior week's activities and plan logistics as well as data capture (ethnographic field notes, video, and photography) for the next week. Each month the core RPP team met to review data collected in the afterschool tinkering class, note the examples and evidence of student learning, and ultimately produce the learning dimensions framework.

The core RPP team consisted of five school-based afterschool educators (including the tinkering co-teacher), an administrative leader from the school, three museum educators (including the tinkering co-teacher), and three museum-based learning researchers. The core group was joined, at different times, by additional staff from the school and museum. The school's afterschool educators were more than twice as likely (94\%) to come from the same communities of color as the students than were its school-day teachers (43\%). Of the core team, four of the six school members were from communities of color and four of the six museum-based members were white. Afterschool educators received stipends of $\$ 500$ per semester for their participation in the project. We include these demographics to acknowledge the potential power dynamics 
of racial and institutional privilege that we needed to account for as we developed trust between museum and afterschool staff. Because trust is the bedrock of productive RPPs (Farrell et al., 2019), in practice this meant that we needed to structure and lead RPP conversations to follow and learn from the interests and insights of the afterschool educators rather than to assume that the museum-based knowledge had priority or even equivalency. To scaffold processes of trustbuilding we created five different meeting structures (weekly co-teaching planning meetings; weekly museum practitionerresearcher debrief meetings; monthly full-RPP team; monthly school-museum project leaders; semesterly school wide poster walks) and established meeting routines including quick personal updates to launch meetings, good food and coffee, and collaborative agenda setting.

\section{Theoretical Framework and Methodology}

We conceptualize learning as an activist project by integrating Stetsenko's (2014, 2015, 2017) "transformative activist stance" with Engeström's (2001) and Engeström and Sannino's (2010) "expansive learning." Expansive learning "puts the primacy on communities as learners, on transformation and creation of culture, on horizontal movement and hybridization, and on the formation of theoretical concepts" (Engeström and Sannino, 2010 , p. 2). It is built on eight main ideas that emphasize collective transformation and that include: collective activity (Leont'ev, 1981); learning by transitioning across the zone of proximal development (Vygotsky, 1978); purposeful, objectbased learning (Leont'ev, 1978); tensions and contradictions as sites for transformation (Il'enkov, 1977, 1982); moving from "the abstract to the concrete" as new ideas are put into practice within the learning activity (building on Davydov, 1990); the role of cultural mediation in learning (Vygotsky, 2004); joint activity that results in new activities (building on Bateson, 1972); and "multi-voiced" processes that bring the ideas, understandings, language, etc. of both the academic and non-academic into debate and conversation (building on Bakhtin, 1982) (Engeström and Sannino, 2010, pp. 4-5). These views on learning as a process and product of collective cultural and social activity help to frame the ways in which making and tinkering classrooms are sites for collaborative ideation and meaning-making. They help us, for example, observe how ideas and strategies ripple through maker spaces, and how collaboration and teamwork serve as the basis for learning and development.

In a maker context, in addition to attending to the broader learning collective, we also attend to individuals who are themselves developing new understandings, skills, identities, and interests. We draw on Stetsenko's "transformative activist stance" as a powerful theoretical tool for overcoming the individual|collective duality that dogs so much educational practice, including some forms of social-cultural theory. Integrating Vygotsky's cultural-historical theory, Bakhtin's dialogical approach, Freire's critical pedagogy, feminism, and other critical and postmodern theory, the transformative activist stance positions learning as an agentive, and also culturally and socially situated, process wherein through efforts to make change in one's world, one makes change in oneself and vice versa. That is, one's world-one's immediate context as well as one's larger historical and cultural context-drive who we are and become; and as we become in these contexts we shape and change both ourselves and the contexts that we resist or embrace. This dialectical conceptualization of learning and development thus both accounts (and calls) for change in the status quo, and challenges the persistent dualisms between the individual and the collective. Being, doing and knowing together constitute processes of becoming, and becoming is a matter of transforming. Hence, our research attends to the ways in which young people experience transformative agency as they both design and build out their ideas, but also contribute those ideas, as well as the skills they are developing, to the larger collective maker community. We thus attend to their creativity, persistence, and skill development.

Pedagogically, in efforts to explicitly support agentive learning, educators must adopt deeply critical stances as they construct and foster the contexts for student agency; this is particularly so in fields, such as science and engineering, that have historically excluded many communities based on gender, race, and other socio-economic and cultural hierarchies. "Rightful presence" is an emerging framework for designing equitable, educational contexts that can support transformative, agentive learning. In their critique of standard approaches to educational equity, Calabrese Barton and Tan note the limitations of "access and inclusion" without a more critical consideration of the contexts for inclusion. Rightful presence, they note (Calabrese Barton and Tan, 2019b, p. 2),

Emerges from critical justice studies of the potentials and limitations of sanctuary cities serving borderland and refugee communities (Squire and Darling, 2013). Sanctuary cities operate on benevolent, guest (immigrant, refugee)-host (citizens) relationships, where municipal legislation formalizes the rights of immigrants and refugees in response to national efforts to enforce dehumanizing immigration laws and practices.

The authors posit that "to restructure new justice-centered futures, hosting needs to shift from merely extending hostcentered rights to actively engaging in processes of re-authoring of rights with newcomers through political struggle" (p. 2). In the school-based maker context this can include purposeful positioning of youth as classroom resources and authors. It helps to focus our observations on the ways in which facilitators honor and build on youth voices and perspectives in their maker activities.

By bringing together researchers and educators across varying roles, responsibilities, and perspectives, this project sought to reflect upon how contexts could be designed and enacted to support student "agency and imagination at the intersection of individual and social dimensions" (Stetsenko, 2020, p. 727). In particular, our group sought to advance theory through the ideas, actions, and efforts taking place on the ground in the afterschool programs: within our collaboration, rooted in commitments to equity in education as a form of activism. We approached this work with the belief that positive social change in educational making contexts could take root only by 
engaging in "practical-critical activity that combines critique and prognostication, analysis and commitment as aspects within one analytical process" (Stetsenko, 2020, p. 731). Our collaborative team was committed to building a more just society through maker education that empowers youth to be critical thinkers and agentive individuals, who can experience and express "rightful presence" and who can impact positive change in their own lives and communities.

Our research sought to document how both the RPP and the tinkering activities were structured and implemented to recognize and leverage participants' interests, prior experiences, and ideas such that they ultimately not only contributed to group thinking and findings but also appropriated and transformed these findings for their own purposes, moving from the "abstract to the concrete" and moving from action to new activity. Although we had a strong cultural-historical theoretical framing in our own work, our conversations focused on the practitioners' theories of learning and not those of Vygotsky or others. Prioritizing practitioners' articulations of learning over academic explications of theory was an attempt to invite a more multi-voiced approach to expansive learning in the shared activity, where the cultural-historical theories of the researchers could be placed in conversation with the ideas of educators, but in ways that did not dominate educators' perspectives or relegate academic ideas as "correct" and practitioners' beliefs as "incorrect."

Our iterative method involved the creation of a series of frameworks or concept maps that evolved from month to month as new student learning data representations were reviewed by the RPP team (see Figure 1). We adapted concept mapping as a practitioner-centered method to surface, name, and organize emerging observations and values. Concept maps are expressions of the mappers' structural knowledge (Passmore, 2004), and a strategy for portraying relationships among key terms (Moore and Readence, 1984) as well as for establishing hierarchies of concepts (Novak and Gowin, 1984). Importantly, they are not measurement or assessment tools and thus are not subject to validity testing inasmuch as they prove to be relevant and useful in practice (but see Tan et al., 2017 for alternative views on their use in assessment). As such, we position them not as technical tools but as thinking tools. Further, as representations of practical knowledge, they may be continually evolving documents, as practice develops and matures. Many have argued that concept maps may be primarily useful for design and for formative evaluation, as well as for communicating values and ideas (Edmondson and Smith, 1996; Plotnick, 1997). We posit that they can serve as a fruitful bridging or boundary object for researchers and practitioners to develop a shared language and

\section{LEARNING DIMENSIONS of Making and Tinkering}

Valuable learning experiences can be gained through making and tinkering.

Use this framework to notice, support, document, and monitor student learning - and to reflect on how your tinkering environment, activities and facilitation may have supported or impeded such outcomes.

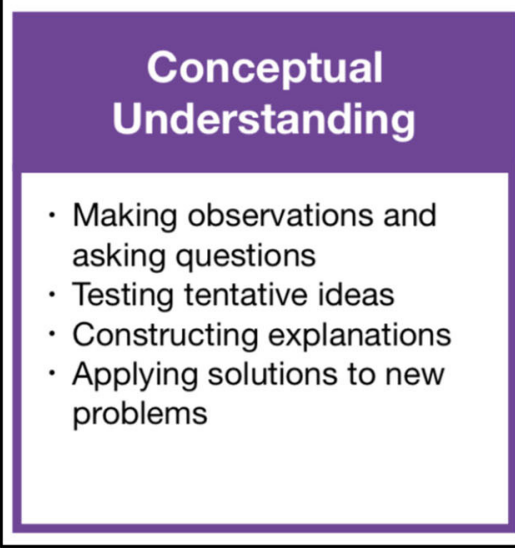

Initiative and Intentionality

- Actively participating

- Setting one's own goal

- Taking intellectual and creative risks

- Adjusting goals based on physical feedback and evidence

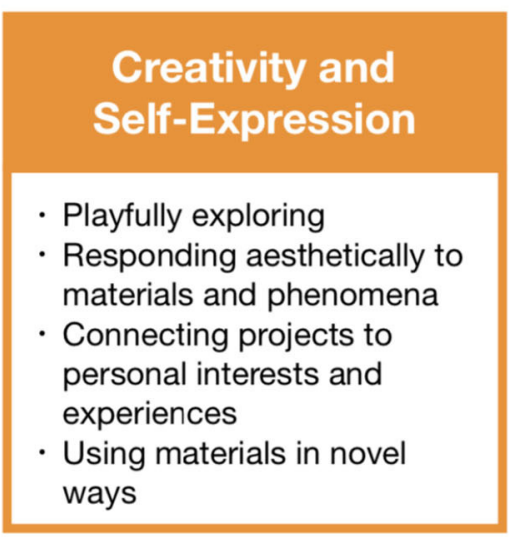

Problem Solving and Critical Thinking

- Trouble shooting through iterations

- Dissecting the problem components

- Seeking ideas, tools, and materials to solve the problem

- Developing work arounds

\section{Social and Emotional}

\section{Engagement}

- Working in teams

- Teaching and helping one another

- Expressing pride and ownership

- Documenting/sharing ideas with others 
TABLE 1 | Articulating shared values for the work.

\begin{tabular}{|c|c|c|}
\hline Question & Coded categories & RPP group generated categories \\
\hline \multirow[t]{2}{*}{ What do you value about youth? } & $\begin{array}{l}\text { Creativity, Open-mindedness, and } \\
\text { Thinking }\end{array}$ & $\begin{array}{l}\text { Creativity; openness; passionate; energetic; deep engagement with } \\
\text { ideas/resourceful; thoughtful; humor }\end{array}$ \\
\hline & Future & $\begin{array}{l}\text { Diversity; mirror for all of us; the future }+ \text { change; being able to work with } \\
\text { kids over time-seeing them develop their identity and ideas }\end{array}$ \\
\hline \multirow[t]{3}{*}{ What do you value about making? } & Creativity & $\begin{array}{l}\text { Creativity; feels like there are no boundaries not just for science, but both; } \\
\text { allows for interdisciplinary connections }\end{array}$ \\
\hline & Learner-driven & Students at the center; character/identity building; expression; access \\
\hline & Hands-on & Hands-on; exploration; fun!; learning outcomes \\
\hline \multirow{2}{*}{$\begin{array}{l}\text { What do you value about afterschool } \\
\text { programming? }\end{array}$} & Flexible and creative & Create/explore; open-ended time; flexibility/freedom/choice; passion \\
\hline & Supportive community & Expanded learning; safety; personal/community; fun \\
\hline
\end{tabular}

understanding. For our RPP, the framework was something that we could "make" together, blending constructs and ideas from both research and practice to describe the kinds of learning behaviors or activities that educators could design for.

\section{RPP ACTIVITIES AND RESULTS}

To advance our call for more direct and central practitioner involvement in research on making, we describe here how the RPP itself was used to leverage practitioners' insights on the value of making for young people's learning and development and how these analyses produced a practitioner-grounded framework for designing for liberatory learning through tinkering. By liberatory learning we mean learning that equips the student to explore and develop their own ideas, following their own methods, toward expanding their personal agency (Freire, 1970; Dobrin, 1999).

\section{RPP Structures and Routines to Amplify Practitioner Voice in Investigations and Analyses}

In this section of the paper we briefly describe some of the RPP structures, routines, and tools we used to develop our collaboration and, over 18 months, to develop the learning dimensions framework used to answer our central research question.

\section{Value Mapping}

At our first monthly RPP team meeting we engaged in a process called Value Mapping (Ryoo and Shea, 2015). In this process we posed key questions to the full RPP team, gave people time to write responses on post-it notes, then collectively shared, categorized and discussed what people had written. Questions we posed in our first meeting included what we valued in afterschool time, what we valued in making, and what we valued in the youth themselves. Through this process we surfaced common ideals and language with respect to young people's creativity, the flexibility inherent to the afterschool hours, and the possibilities for learner-driven maker activities (see Table 1). This kickoff meeting served to set the tone for the collaborative and democratic nature of the inquiry as we worked to develop greater specificity about what we collectively saw and valued in student learning in tinkering.
Importantly, in this initial meeting the centrality of creativity within a flexible and supportive context came through loudly, including the overlapping characteristics of the processes of making and of the afterschool environment.

\section{Data Review Meetings}

The second author collected data weekly in the after school tinkering program and prepared it for sharing at the monthly 90-min RPP data review meetings. In the first review meeting we shared two field note excerpts. The first described a student who was learning how to thread a needle and sew circuitry onto a felt heart. The one-page excerpt provided a narrative description of the museum educator's interactions with the female student, quotes of what they said to each other (including new vocabulary that the educator shared related to sewing), and how the educator talked the student through the sewing process. The second 1.5 page excerpt described a pair of female students who were struggling to take apart a mechanical toy and make sense of its parts. The excerpt described how the facilitator demonstrated how to use a screwdriver, how the wires attached to a switch, and encouraged them through what she recognized as a "hard" task.

As the team made observations about what they could see in the transcripts they reflected on evidence of student persistence, problem-solving, and designing. We recorded on chart paper everybody's observations. At each month's data review meeting we added to the concept map, organizing and condensing as we went, to evolve, over three semesters, an articulation of the key ideas shown in Figure 2. As can be seen, in the second semester, we made an effort to more explicitly connect practitioners' observations of student learning to constructs identified in the formal science education literature (see National Research Council, 2012), in order, we thought, to facilitate the bridging between afterschool and school day, as well as between research and practice.

\section{Data Representations}

We began, as described above, by using printed field notes that included descriptions and direct quotes of facilitators working with students. But practitioners found these to be cumbersome to read, so by the fourth data meeting we switched to using raw video excerpts. Later we created edited power points, with embedded video clips, that showed the progression of student activity over time. 


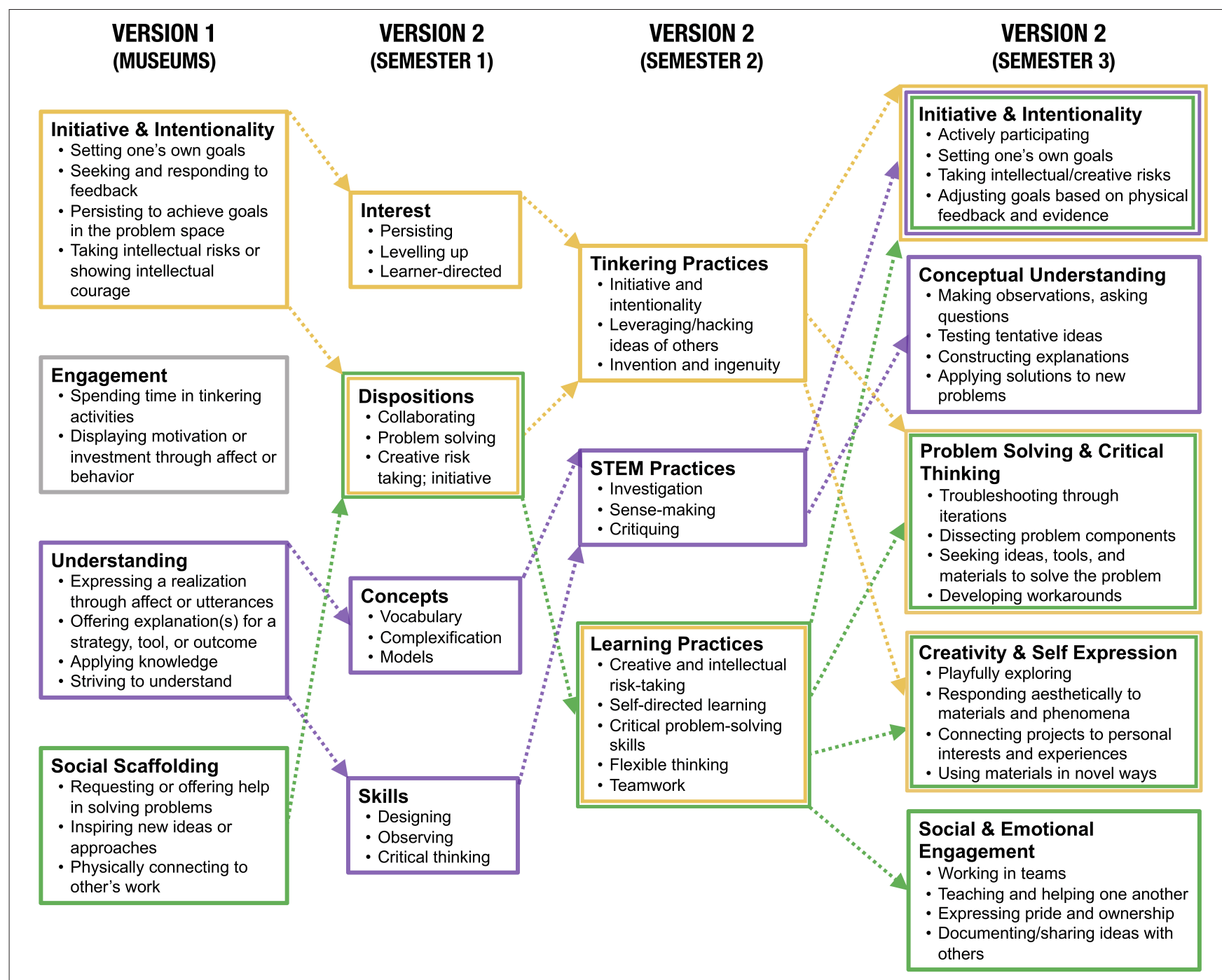

FIGURE 2 | Final version of the evolving learning dimensions constructs during each semester of the project.

While editing involved interpretation on the part of the researchers in selecting which moments to include, the practitioners responded most positively to, and were able to do more sense-making with, representations of a longer arc of activity. Reflections moved fluidly between observing student struggles and accomplishments, to focusing on the choices and actions of the adult facilitators in making such student moves possible. Afterschool educators repeatedly brought their knowledge of the students themselves to the sense-making process. For example, in one video clip documenting a student who was creating a paper circuit for the first time, using a coincell battery, copper tape, and small LEDs (see still images from the video in Figure 3), educators noticed how a normally reserved and shy student discussed and expressed pride in her work. They also noted an unusual level of persistence as she mastered soldering the joints of her circuit, and they considered how the facilitator's timely introduction of both tools and assistance seemed critical for helping this normally reserved student to continue and succeed. Thus, they focused on the transformative possibilities afforded by making, and on the ways in which facilitators supported developing forms of agency. The resulting observations were added to the next iterations of the framework.

\section{Data Walks}

To engage the school-day educators and administrators with the work of the afterschool educators and the RPP itself, each semester we spent the last 2-3 sessions creating posters for a school-wide "data walk" where the afterschool educators shared posters describing the activities they were leading and the student learning that they were capturing through video, photography, or samples of student work. The tinkering class was one of the posters presented. In this process, museum staff took on roles such as helping to tape, glue, or decorate posters, as well as probing practitioners to elaborate their goals for student learning, how they designed activities to meet those goals, and what kinds of evidence they saw of whether or not students were successful in meeting the goals. The data walks proved productive not only for engaging school personnel with the professional value of the 

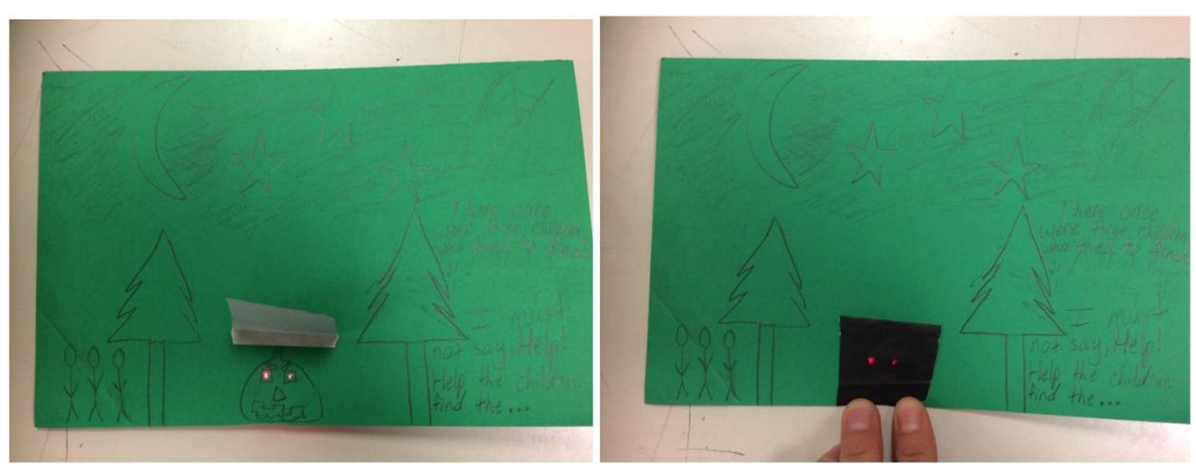

FIGURE 3 | Stills from video depicting a student's learning trajectory while creating a paper circuit.

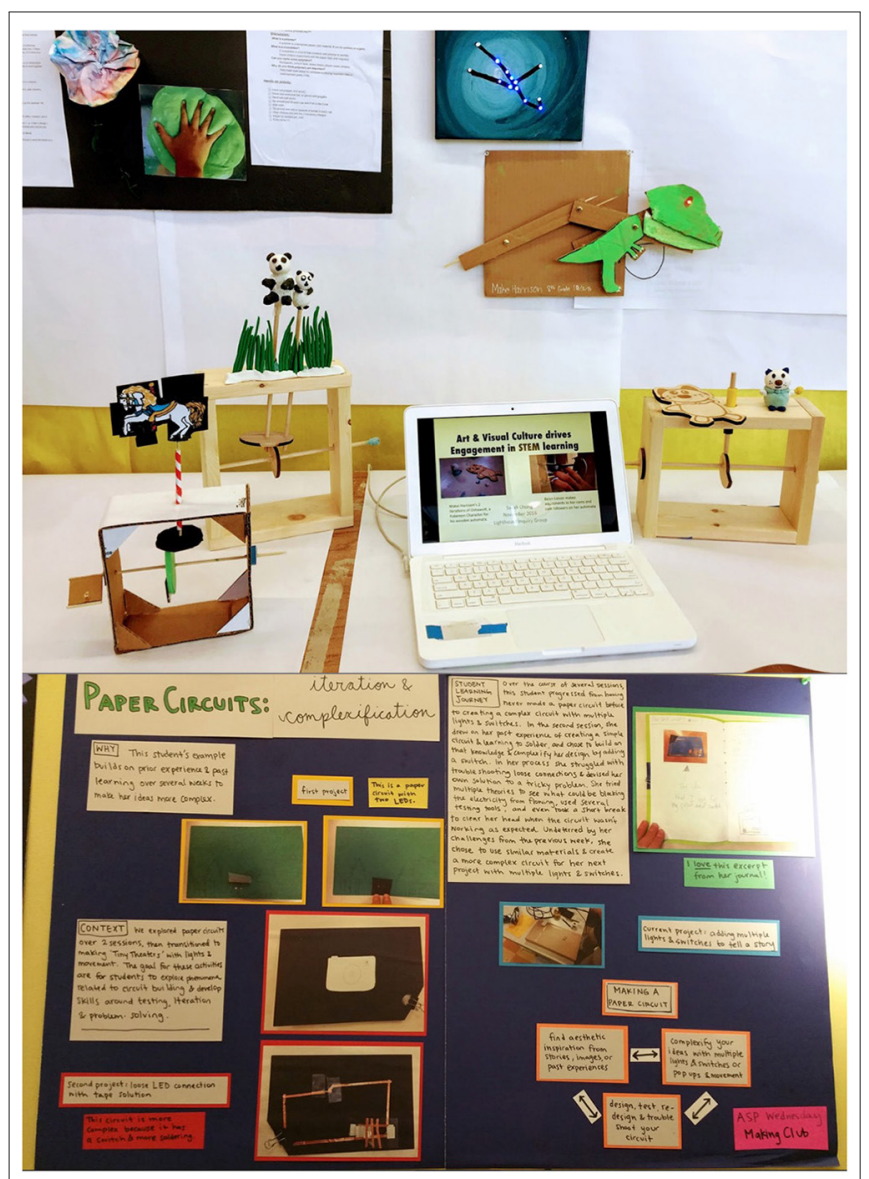

FIGURE 4 | First and third semester posters demonstrating growing attention to and detail of student learning processes.

afterschool maker programs but also for documenting, over three semesters, the increasing specificity, use of data, and attention to learning among the RPP afterschool educators (see Figure 4). Practitioners gradually came to draw on the learning dimensions for analyzing student activity in their programs.

While the first semester presentations made reference to emerging ideas about learning in making contexts that had surfaced in our monthly RPP data review meetings, by the final semester posters drew directly and extensively from the shared language the group had developed to make the fruits of their pedagogical practices more visible to others. For example, in the second semester an afterschool instructor created a video illustrating, over time, her students' process of designing, building, and trouble-shooting a large ping-pong ball installation in the school's foyer. As compared with her first semester poster, which focused on describing the activities, the second semester poster included extensive examples of evidence of student learning in the activities. She included photos of student journals, examples of specific problems that students solved or innovations they made, and even displayed a short video next to her poster accompanied by a thick scrapbook filled with clippings of students' design and problem solving notes. She also became more specific in the language she used to explain the learning that was happening, pointing out specifically when she saw "creative problem solving," "persistence," and "teamwork."

In a final reflection conversation shared during the last RPP data meeting of the third semester, several of the educators referenced the ways that they used the learning dimensions to guide their thinking:

\begin{abstract}
"My approach to lesson planning changed a lot. Since this [data review] group, I'm now looking for ways to push the learning dimensions-like focusing on and supporting problem solving, not just focusing on making paper hearts." -Joelle

"After participating in the inquiry group, I see students differently. Especially after using the learning dimensions framework, I find myself noticing and seeing things like 'creativity' etc." -Deirdre
\end{abstract}

\section{Development of a Practitioner-Oriented Learning Dimensions Framework}

In this section of the paper we show how we adapted concept mapping to surface afterschool practitioner views on what kinds of learning were happening, and organized it into a learning dimensions framework intended to bridge afterschool and school values for student learning.

Our intent was to move beyond a museum-based framework that the museum practitioners had previously co-developed, which they valued yet felt was missing key aspects of the tinkering experience. The data informing the museum framework reflected 
the limitations of many drop-in museum-based programs: We did not know the participants, did not know what they brought to the experience or how it might have contributed to a longer arc of development. Strictly adhering to the video data documenting these short-term museum engagements provided strong evidence of some but not all of the possibilities for learning in tinkering. Notably the creative and problem-solving elements-words that defined tinkering-were absent from the initial framework. Data capture in the afterschool environment allowed for the examination of student activity and development over time, for exploring ideas with youth from historically marginalized communities, and for working with educators who knew the youth well.

In our RPP data review meetings, we initially organized RPP team observations using constructs from two research syntheses published by the US National Academy of Scienceone on science learning in formal classrooms (National Research Council, 2007) and the other in informal environments (National Research Council, 2009)_namely, science concepts, skills, interests, and dispositions. For example, evidence of students' persistence, collaboration, flexible thinking, and commitment was linked to "Dispositions," while using models or complexifying circuitry was linked to "Concepts." The final first semester framework (see Figure 2) listed 20 constructs grouped into the initial four over-arching themes. The document was representative of the group's observations, ideas, and values but was unwieldy.

In the fall semester we reconstituted the RPP group and once again met monthly to review data collected from a semester long tinkering course focused on cause-and-effect. In an effort to simplify the framework, we clustered the ideas surfaced during the first semester into three groups of practices: tinkering, STEM, and learning. This new representation included one new idea contributed by the museum staff (a focus on hacking the ideas of others), but otherwise streamlined and regrouped existing constructs from the previous semester. For example, we clustered the full set of eight scientific practices identified by the National Research Council (2012) Framework for K12 Science and Engineering, into three clusters identified by McNeill et al. (2015).

Shortly thereafter, in discussions about how radical the representational changes were from the first to the second semester, we began to consider if and how the new afterschool framework related to the previous museum-based framework, which had attracted a good amount of attention particularly in the museum world. We were concerned about possibly confusing the field with two such different representations (museum and afterschool) coming out of one group, even though they had been developed under very different circumstances. In comparing our concept maps to the museum framework we found overlap, but also difference, notably the inclusion of creativity and problemsolving in the former.

To reconcile the two, we tried to map the full range of constructs to the original museum framework. This led us to create the new categories of Creativity \& Self Expression and Problem Solving \& Critical Thinking. We also renamed the theme of Social Scaffolding to Socio-Emotional Engagement, and included indicators more relevant to an afterschool program and less limited to a drop-in one. In addition to encompassing the constructs found in our previous version, these new broader categories allowed us to probe the particular dimensions of tinkering, such as the aesthetic demands of materials and how aesthetic choices often triggered unanticipated and cascading design challenges; or how responding to the physical properties of materials in iterative feedback loops was central to the tinkering experience; and the deeply personal nature related to how ideas drive activity. This document satisfied our concern about confusing the field of practice with a completely different representation of learning through tinkering.

We called on the graphic skills of one of our colleagues to produce the version that is currently in use, affectionately known as the Monopoly cards (Figure 1). We have found this version to be easy to use with practitioners in professional development workshops. Practitioners use it as a lens to analyze and make design choices about given activities as well as about entire sequences of activities. That is, some activities may be particularly rich in one or more but not all of the dimensions; whereas over the course of time one would expect that tinkering programs would be designed to afford most or all of them. What students do is of course shaped by the interests and resources they bring to the experience. But the final version of the learning framework allows educational designers to be intentional about allowing options for all learners.

In the current version of the learning dimensions framework the researchers' theoretical commitments to purposeful and transformative activity as a driver of activity is embedded in the constructs of initiative \& intentionality as well as creativity \& self-expression. Our conceptualization of the dialectical role of cultural tools (e.g., indicators listed in the constructs of conceptual understanding and problem solving \& critical thinking) and social contexts (e.g., indicators listed in the construct of social and emotional engagement) in advancing transformational purposes are here, albeit in terms that came from the practitioners who design and implement the work. We shared the new framework with teachers at the school and they responded positively to both the overarching constructs as well as the indicators, pointing to the relevance of the indicators for student learning, engagement, and agency during the school day.

\section{CONCLUSION}

Through the activities described above, the RPP led to the development of a learning dimensions framework that has been translated into 12 languages to date and is today used in professional learning settings and programs internationally.

The learning dimensions framework produced through this RPP has been taken up in practice in several important ways. It serves to anchor the ongoing maker education professional development programs offered by the museum. These programs have reached thousands of participants internationally over the last year, in settings from Milan, to Singapore, to Beijing. Additionally the framework has been incorporated into a MOOC offered on Coursera, and repeated every 12 weeks, that has reached 40,000 participants so far. The framework has also been used to inform the development of a reflective practice 
tool by the Lego Foundation, working internationally with ministries of education in Africa, Europe, Ukraine, and Mexico. Finally, it is being piloted in professional training programs offered by MakerEd, the nation's leading resource for maker education. Across all of these workshops, the framework has been introduced to scores of educators who then use the tool with their colleagues to reflect on and refine their own maker education practices.

The structures and systems of schooling and afterschool continue to challenge efforts to fully reframe educational settings to support transformative agency. Even when explicit attention is paid to achieving equity, as Calabrese Barton and Tan (2019b, p. 2) recently noted "Thus far, equity frameworks in the teaching and learning of academic subjects have minimally disrupted the racial, gendered, and linguistic hierarchies in education, while mostly maintaining these oppressive power dynamics." Yet these authors, among many others, note the potentially transformative power of making as a curricular approach that allows students to articulate and respond to their social, cultural, and political world. Specifically they have shared numerous examples of how students used making programs to transform the environments that oppressed them, such as students designing and building an "occupied" light for bathrooms in schools where students are not allowed to lock the bathroom doors (Calabrese Barton and Tan, 2019a) or students designing and building a solarpowered light-up scooter to navigate badly lit city streets in their neighborhoods (Calabrese Barton and Tan, 2018). While the projects explored in our study were not rooted in challenging forms of systemic oppression, students were able to challenge assumptions of what science and engineering looks like, who does science and engineering, and how it can be used to explore and express ideas. These efforts thus contributed to identity shifts over time, and advanced agentive teaching and learning. They provided opportunities for creativity, persistence, teamwork and collaboration among many other activities and stances deeply linked to transformative learning and development (Engeström and Sannino, 2010; Stetsenko, 2014).

The RPP described here makes a contribution to the literature in providing descriptions of how intentional structures to foster relationships and generate original data analysis can amplify the voices and perspectives of maker practitioners and inform research on learning through tinkering. In addition to developing a better tool for the field, today used widely in practice, the pedagogical practices and discourse of participants became more

\section{REFERENCES}

Bakhtin, M. M. (1982). The Dialogic Imagination: Four Essays by M.M. Bakhtin. Austin, TX: University of Texas Press.

Bateson, G. (1972). Steps to an Ecology of Mind. New York, NY: Ballantine Books.

Berland, M. (2016). "Making, tinkering, and computational literacy," in Makeology: Makerspaces as Learning Environments, Vol. 2. eds. K. Peppler, E. R. Halverson, and Y. B. Kafai (New York, NY: Routledge), 196-205. doi: 10.4324/9781315726496-12

Bevan, B. (2017). The promise and the promises of Making in science education. Stud. Sci. Educ. 53, 75-103. doi: 10.1080/03057267.2016.1275380

Bevan, B. (2019). "Data as a driver of reflection: research and practice tools for identifying learning and design principles," in The Reflective Museum evidence-based. The paper describes how researchers released a strong grip on theory to allow for the language and ideas from practice to emerge and define the work. They also took a strong role in simplifying the tool so that it would be useful in practiceworking with practitioners' ideas to connect them to existing learning frameworks as well as to the particularities of tinkering, not all of which surfaced during our afterschool data sessions. This is an example of how joint perspectives and expertise can blend, in RPPs, to advance thinking.

While research on making continues to expand, we suggest that it is critical that researchers integrate and leverage the voices of practitioners to build on their deep knowledge of students and their larger learning ecology. In many ways practice is still ahead of research on making. Research-practice partnerships provide one fruitful way to begin to close this gap.

\section{ETHICS STATEMENT}

The studies involving human participants were reviewed and approved by Exploratorium's external IRB. Written informed consent to participate in this study was provided by participating adults and youth, as well as by the guardians of participating youth.

\section{AUTHOR CONTRIBUTIONS}

The work shared here is the product of a collaboration led by the authors of the paper, working with colleagues listed in the Acknowledgments. All authors contributed to the article and approved the submitted version.

\section{FUNDING}

National Science Foundation (1626365) and the Overdeck Foundation jointly funded the work described in this paper.

\section{ACKNOWLEDGMENTS}

The authors would like to acknowledge the active participation and contributions of the full RPP team, whose work and ideas are represented here, including: Luigi Anzivino, Dayana Becerra, Nicole Bulalacao, Michelle Choi, Sarah Chung, Amy Dobras, Deanna Gelosi, Asatu Hall, Gary Hall, Joette Harris, Ryan Jenkins, Laila Jenkins-Perez, Lianna Kali, Jovan Lowe, Juan Perez, Mario Rodriguez, Jessica Gray Schipp, and Steve Stokes.

Practitioner: Expanding Practice in Science Museums, eds L. W. Martin, L. U. Tran, and D. Ash (New York, NY: Routledge), 64-80.

Bevan, B., Gutwill, J. P., Petrich, M., and Wilkinson, K. (2015). Learning through STEM-rich tinkering: findings from a jointly negotiated research project taken up in practice. Sci. Educ. 99, 98-120. doi: 10.1002/sce. 21151

Bevan, B., and Penuel, W. R. (Eds.). (2018). Connecting Research and Practice for Educational Improvement: Ethical and Equitable Approaches. New York, NY: Routledge.

Bevan, B., Ryoo, J. J., and Shea, M. V. (2017). What-If? Building creative cultures for STEM making and learning. Afterschool Matters Spring, 1-8.

Blikstein, P. (2013). "Digital fabrication and "making" in education: the democratization of invention," in FabLabs: Of Machines, Makers and 
Inventors, eds J. Walter-Herrmann and C. Büching (Bielefeld: Transcript Publishers), 1-21.

Buchholtz, B., Shively, K., Peppler, K., and Wohlwend, K. (2014). Hands on, hands off: gendered access in crafting and electronics practices. Mind Cult. Act. 21, 278-297. doi: 10.1080/10749039.2014.939762

Calabrese Barton, A., and Tan, E. (2018). Stem-Rich Maker Learning: Designing for Equity with Youth of Color. New York, NY: Teachers College Press.

Calabrese Barton, A., and Tan, E. (2019a). Designing for rightful presence in STEM: community ethnography as pedagogy as an equity-oriented design approach. J. Learn. Sci. 28, 616-658.

Calabrese Barton, A., and Tan, E. (2019b). Designing for rightful presence in STEM: the role of making present practices designing for rightful presence in STEM: the role of making present practices. J. Learn. Sci. 28, 1-43. doi: 10.1080/10508406.2019.1591411

Coburn, C. E., and Penuel, W. R. (2016). Research-practice partnerships in education: outcomes, dynamics, and open questions. Educ. Res. 45, 48-54. doi: 10.3102/0013189X16631750

Davydov, V. V. (1990). Types of Generalization in Instruction: Logical and Psychological Problems in the Structuring of School Curricula. Reston, VA: National Council of Teachers of Mathematics.

Dobrin, S. I. (1999). "Paralogic hermeneutic theories, power, and the possibility for liberating pedagogies," in Post-Process Theory: Beyond the Writing Process Paradigm, ed. T. Kent (Carbondale, IL: Southern Illinois UP), 132-48.

Edmondson, K., and Smith, D. E. (1996). Concept mapping to facilitate veterinary students' understanding of fluid and electrolyte disorders. (Report No. TM 025 698). Paper presented at the annual meeting of the American Educational Research Association, New York (ERIC Document Reproduction Service No. ED 400 315).

Engeström, Y. (2001) Expansive Learning at work: toward an activity theoretical reconceptualization. J. Educ. Work 14, 133-156. doi: 10.1080/13639080020028747

Engeström, Y., and Sannino, A. (2010). Studies of expansive learning: foundations, findings and future challenges. Educ. Res. Rev. 5, 1-24. doi: 10.1016/j.edurev.2009.12.002

Farrell, C. C., Harrison, C., and Coburn, C. E. (2019). "What the hell is this, and who the hell are you?" Role and identity negotiation in research-practice partnerships. AERA Open 5, 1-13. doi: 10.1177/2332858419849595

Freire, P. (1970). Pedagogy of the Oppressed. (M. B. Ramos, Trans.) New York: Continuum

Gutwill, J. P., Hido, N., and Sindorf, L. (2015). Research to practice: observing learning in tinkering activities. Curator: The Museum J. 58, 151-168. doi: $10.1111 /$ cura.12105

Il'enkov, E. V. (1977). Dialectical Logic: Essays in its History and Theory. Moscow: Progress.

Il'enkov, E. V. (1982). The Dialectics of the Abstract and the Concrete in Marx's 'Capital'. Moscow: Progress.

Iversen, O., Smith, R., Blikstein, P., Katterfeldt, E. S., and Read, J. (2016). Digital fabrication in education: expanding the research towards design and reflective practices. Int. J. Child-Comp. Interact. 5, 1-2. doi: 10.1016/j.ijcci.2016.001

Kirshner, B., Pacheco, J., Sifuentes, M., and Hildreth, R. (2018). "Rethinking "the community" in university partnerships: case studies from CU engage," in Connecting Research and Practice for Educational Improvement: Ethical and Equitable Approaches, eds B. Bevan and W. R. Penuel (New York, NY: Routledge), 85-99. doi: 10.4324/9781315268309-6

Leont'ev, A. N. (1978). Activity, Consciousness, and Personality. Englewood Cliffs: Prentice-Hall.

Leont'ev, A. N. (1981). Problems of the Development of the Mind. Moscow: Progress.

Martin, L. (2015). The promise of the Maker Movement for education. J. Pre-Coll. Eng. Educ. Res. (J-PEER) 5. doi: 10.7771/2157-9288.1099

McNeill, K. L., Katsh-Singer, R., and Pelletier, P. (2015). Assessing science practices - moving your class along a continuum. Sci. Scope 39, 21-28. doi: 10.2505/4/ss15_039_04_21

Moore, D. W., and Readence, J. E. (1984). A quantitative and qualitative review of graphic organizer research. J. Educ. Res. 78, 11-17. doi: 10.1080/00220671.1984.10885564

National Research Council. (2007). Taking Science to School: Learning and Teaching Science in Grades K-8. Washington, DC: National Academies Press.

National Research Council. (2009). Learning Science in Informal Environments: People, Places, and Pursuits. Washington, DC: The National Academies Press.
National Research Council. (2012). A Framework for K-12 Science Education: Practices, Crosscutting Concepts, and Core Ideas. Washington, DC: The National Academies Press.

Novak, J. D., and Gowin, D. B. (1984). Learning How to Learn. New York, NY: Cambridge University Press.

Passmore, G. (2004). Extending the power of the concept map. Alberta J. Educ. Res Winter 50, 370-390. Available online at: https://searchproquest-com.offcampus.lib.washington.edu/docview/228591647/abstract/ 97B9A467465B4585PQ/1?accountid=14784

Peppler, K., Halverson, E. R., and Kafai, Y. B. (2016). Makeology: Makerspaces as Learning Environments, Vol. 1. New York, NY: Routledge.

Petrich, M., Wilkinson, K., and Bevan, B. (2013). "It looks like fun, but are they learning?" in Design, Make, Play: Growing the Next Generation of STEM Innovators, eds M. Honey and D. Kanter (New York, NY: Routledge), 50-70.

Plotnick, E. (1997). "Concept mapping: a graphical system for understanding the relationship between concepts," in ERIC Digest. Retrieved from: https://files. eric.ed.gov/fulltext/ED407938.pdf

Resnick, M., and Rosenbaum, E. (2013). “Designing for tinkerability," in Design, Make, Play: Growing the Next Generation of STEM Innovators, eds M. Honey and D. Kanter (New York, NY: Routledge), 163-181.

Resnick, M., and Silverman, B. (2005). "Some reflections on designing construction kits for kids," In Proceedings of Interaction Design and Children Conference, eds M. Eisenberg and A. Eisenber, 117-122. doi: 10.1145/1109540.1109556

Ryoo, J. J., and Shea, M. (2015). Value Mapping: An Activity for Surfacing Power Dynamics and Diverse Perspectives in Research-practice Collaborations. San Francisco, CA: Exploratorium.

Squire, V., and Darling, J. (2013). The "minor" politics of rightful presence: justice and relationality in City of Sanctuary. Int. Polit. Sociol. 7, 59-74. doi: 10.1111/ips.12009

Stetsenko, A. (2014). “Transformative activist stance for education: inventing the future in moving beyond the status quo," in Psychology in Education: Critical Theory $\sim$ Practice, ed T. Corocoran (Rotterdam: Sense), 181-198. doi: 10.1007/978-94-6209-566-3_12

Stetsenko, A. (2015). "Theory for and as social practice of realizing the future: implications from a transformative stance," in The Wiley Handbook of Theoretical and Philosophical Psychology, eds J. Martin, J. Sugarman, and K. Slaney (New York, NY: Wiley), 102-116. doi: 10.1002/9781118748213.ch7

Stetsenko, A. (2017). The Transformative Mind: Expanding Vygotsky's Approach to Development and Education. New York, NY: Cambridge University.

Stetsenko, A. (2020). Hope, political imagination, and agency in marxism and beyond: explicating the transformative worldview of ethico-ontoepistemology. Educ. Philos. Theory. 52, 726-737. doi: 10.1080/00131857.2019.1654373

Tan, S., Zimmermann, R., and Erdimez, Ö. (2017). The use of concept maps as a tool to measure higher level thinking skills in elementary school science classes. J. Educ. Gift. Young Sci. 5. doi: 10.17478/JEGYS.2017.60

Tseng, V., Fleischman, S., and Quintero, E. (2018). "Democratizing evidence in education," in Connecting Research and Practice: Developing More Ethical and Equitable Approaches to Educational Improvement, eds B. Bevan and W. R. Penuel (New York, NY: Routledge).

Vossoughi, S., Hooper, P., and Escudé, M. (2016). Making through the lens of culture and power: towards transformative visions for educational equity. Harv. Educ. Rev. 86, 206-232. doi: 10.17763/0017-8055.86.2.206

Vygotsky, L. S. (1978). Mind in Society: The Development of Higher Psychological Processes. Cambridge: Harvard University Press.

Vygotsky, L. S. (2004). "The history of the development of higher mental functions," in The Essential Vygotsky, eds. R. W. Rieber, and D. K. Robinson (New York, NY: Kluwer Academic/Plenum Publishers), 359-400.

Conflict of Interest: The authors declare that the research was conducted in the absence of any commercial or financial relationships that could be construed as a potential conflict of interest.

Copyright (c) 2020 Bevan, Ryoo, Vanderwerff, Wilkinson and Petrich. This is an open-access article distributed under the terms of the Creative Commons Attribution License (CC BY). The use, distribution or reproduction in other forums is permitted, provided the original author(s) and the copyright owner(s) are credited and that the original publication in this journal is cited, in accordance with accepted academic practice. No use, distribution or reproduction is permitted which does not comply with these terms. 